\title{
Schopenhauer, Wagner e a Ópera: \\ algumas dificuldades com a metafísica musical a partir de uma abordagem psicolinguística
}

\author{
Tristan Torriani \\ Doutor em Filosofia pela UNICAMP e pela Otto Von Guericke Universität Magdeburg \\ Professor (IA-UNICAMP)
}

Resumo: Neste artigo primeiramente procuro explicar quais são as razões que tornam pretensões metafísicas em geral muito problemáticas, a maior delas sendo a de que o metafísico não tem como fazer afirmações sobre a coisa-em-si sem estar ele mesmo interpretando fenômenos a partir da mediação de conceitos que sempre envolvem mente e linguagem. A nítida cisão entre pensamento e linguagem em Schopenhauer faz com que qualquer suposta cognição metafísica teria que ficar presa ao nível pré-verbal ou sensoriomotor, e por isso de modo algum poderia ser aceita como tendo validade universal ou absoluta. A seguir discuto a apropriação wagneriana da concepção schopenhaueriana da ópera, em que se evidencia um descompasso considerável entre o compositor e o filósofo.

Palavras-Chave: Schopenhauer; Wagner; Estética Musical.

Abstract: In this paper I initially try to explain what makes metaphysical claims so problematic. The major difficulty is that the metaphysician cannot make statements about the thing-in-itself without interpreting phenomena by means of concepts that always involve mind and language. The clearcut separation Schopenhauer draws between thought and language consigns any supposed metaphysical cognition to the domain of pre-verbal or sensory-motor cognition, which could hardly claim absolute or universal validity. I then examine Wagner's appropriation of Schopenhauer's views on opera and this reveals great differences between the composer and the philosopher.

Keywords: Schopenhauer; Wagner; Musical Aesthetics.

\section{Introdução}

A filosofia da música hoje se caracteriza por problemas que não são apenas estéticos, mas também semânticos e ontológicos. Na medida em que a música continua a ser uma arte e que por 'objeto de arte' se entenda algo que se dirija a uma sensibilidade estética para ser acolhida e ajuizada, os problemas de significação e de existência das obras musicais permanecem, porém, ainda sob a égide da estética. A valorização da música por seu suposto valor cognitivo, moral ou sócio-cultural distorce o propósito da música enquanto arte. O músico e o público do século XXI têm acesso fácil a uma quantidade inesgotável de produções musicais dos mais diversos tipos, mas há uma dificuldade muito grande em lidar criticamente com os discursos sobre música, que em tantos casos são mistificadores. A origem histórica dessa mistificação da música não pode ser 
tratada aqui com o rigor e detalhamento necessários. Do ponto de vista lógico, podemos caracterizar a mistificação da música como qualquer teorização que procure atribuir à escuta e apreciação de peças um lastro indemonstrável, e isso por meio de conceitos inadequados. Neste sentido, já a teoria pitagórica da música (inaudível!) das esferas fomentava algo próximo ao que da perspectiva científica atual consideraríamos mistificação, pois propunha correspondências ocultas entre razões numéricas existentes entre corpos celestes e as divisões da oitava numa corda tesa. $\mathrm{O}$ entusiasmo dos filósofos e escritores alemães românticos pela música é compreensível, pois ela parecia até então não ter tido a sua autonomia enquanto arte suficientemente reconhecida (sobretudo devido à sua subordinação à poesia) e suas características não-representacionais, afetivas, temporais e mesmo espaciais, estavam então sendo exploradas e ampliadas por compositores ousados como Beethoven e Schubert. A reação formalista contra a estética do sentimento daí resultante teria que aguardar até 1854 quando da publicação do ensaio de Hanslick sobre o belo musical. Tanto Schopenhauer quanto Wagner encontravam-se nesse contexto em que estavam ocorrendo tantos desdobramentos na linguagem tanto filosófica quanto musical. ${ }^{1}$ A questão que precisa nos orientar aqui, porém, é até que ponto uma metafísica da música tem viabilidade hoje enquanto discurso metamusical. A seguir tentarei indicar as dificuldades envolvidas na vinculação entre a especulação metafísica e a estética musical.

\section{Aporias da semântica representacionalista e da ontologia realista absoluta (Realismo relativista)}

Tanto Schopenhauer quanto Wagner acreditavam que podiam ter acesso imediato à coisa-em-si, ou seja, à realidade enquanto tal, independentemente da perspectiva e interpretação de algum sujeito. A cognição da "essência intrínseca das coisas" pressupõe a superação da relatividade subjetiva e o alçamento do conhecimento para um nível supostamente mais elevado, que forneceria então saber absoluto. Já para Kant, mas ainda mais após as objeções de Nietzsche e do Wittgenstein tardio, porém, esta pretensão se mostra insustentável, pois não há como ter acesso conceitualmente interpretado à realidade exterior sem a mediação da mente e da linguagem, que assim constroem para o sujeito uma perspectiva a partir da qual este acesso à realidade ocorre.

1 R. Safranski chega a falar dos "anos loucos da filosofia" (wilden Jahren der Philosophie). 
Esta constatação pode causar inconformismo entre um contingente significativo de amantes da sabedoria e buscadores da verdade. Pode-se questionar se as objeções antiabsolutistas possuem de fato o caráter decisivo que pretendem ter. Por isso torna-se necessário recapitulá-las antes de proceder a discutir Schopenhauer e Wagner.

Num primeiro momento precisamos ter clareza sobre porque a filosofia se apresenta como disciplina tão confusa. Desde o seu nascimento entre as artes discursivas na Grécia havia uma consciência de que a linguagem era indispensável para que sequer pudesse haver filosofia. Platão estabelece o diálogo argumentado como prática comunicativa (senão até como instituição) para que dúvidas conceituais pudessem ser tematizadas e ocasionalmente até resolvidas. No entanto, o conceito de pensamento tardou muito para ser formulado de modo a incorporar atos comunicativos como possuindo nele uma função constitutiva, e não apenas mediadora. Ou seja, o ato comunicativo inclui elementos sonoros e formais como palavras e sentenças enquanto componentes indispensáveis ao pensamento do indivíduo. Além disso, partimos da linguagem e não da mente para analisar nossos conceitos. Até o século XX, com raras exceções, tendeu-se a atribuir aos nossos estados mentais uma suposta primazia e autonomia com relação aos atos que utilizamos nas nossas interações comunicativas. Deste modo, o ato de emitir um grupo de fonemas era entendido como tendo apenas uma função mediadora, de "veicular", "transmitir", ou "expressar" um pensamento ou significado entendido enquanto estado mental já pré-existente à comunicação. Pressupunha-se que dois interlocutores poderiam vir a "compartilhar" o mesmo pensamento embora usassem como etiquetas palavras, por ex., de línguas diferentes, para comunicá-lo, pois haveria uma "razão universal" que transcenderia as mentes individuais. Não havia, porém, modo de verificar se esses pensamentos ou significados eram realmente iguais, pois os critérios de identidade semântica entre eles não são intersubjetivamente controláveis se forem abordados como puros estados mentais sem algum vínculo com o comportamento dos sujeitos e com regras semânticas da linguagem em questão.

Uma característica central da filosofia moderna a partir de Descartes se torna então a certeza subjetiva, não obstante as dúvidas de um Hume sobre o si-mesmo. Em Locke a linguagem funciona efetivamente como um sistema de etiquetas para "significar", "representar" ou "estar por" idéias entendidas enquanto estados mentais. Nunca ocorreu ao filósofo britânico se perguntar como poderíamos saber que uma 
palavra de fato significaria uma idéia sem termos antes feito uso da própria linguagem. Toda teoria semântica mentalista, ou seja, que entende o significado como sendo constituído por estados mentais pré-existentes, pressupõe já o funcionamento intersubjetivamente bem-sucedido da linguagem antes de explicar como ela funcionaria. Sem linguagem, não tenho como saber se a idéia de vermelho é do vermelho, pois nessa cognição já está envolvido o uso de palavras para cores como o termo 'vermelho'. Dependo também da atenção de um interlocutor para estabelecer uma relação comunicativa na qual essa regra semântica para o termo irá valer.

Outro problema da filosofia moderna é o conceito de representação (Vorstellung em alemão), que se vincula a uma teoria correspondencionista da verdade. Nossos estados mentais seriam concebidos como tendo a capacidade de "espelhar" ou "retratar" a realidade. Uma proposição verdadeira, vinculando sujeito e predicado, teria algum tipo de correspondência com o mundo real que garantiria o seu valor de verdade. Esta concepção permite a busca pela verdade do assim chamado philalethes e pode assim adquirir uma dimensão existencial: morrer pela verdade de uma causa política ou religiosa, por exemplo.

No caso do conceito de representação, tão central para Schopenhauer, carecemos de um acesso intersubjetivamente controlável para decidir se a representação representa algo ou não. Assim, quando Schopenhauer fala em representações intuitivas e representações abstratas (conceitos entendidos como representações de segunda ordem ou representações de representações), já houve um descolamento entre mente e linguagem que dá margem para todo tipo de aparente explicação metafísica, mesmo que no nível da descrição empírica haja um esmero muito grande com os detalhes, como quando ele se ocupa das ciências da época. No discurso filosófico do pensador moderno mentalista típico, a linguagem opera irrefletidamente no decorrer de extensos textos, enquanto que se acredita poder estabelecer relações de necessidade, universalidade e objetividade através da combinação de estados mentais supostamente representacionais. Ao mesmo tempo em que todos esses argumentos estão sendo vertidos na linguagem, não se reconhece a ela nenhum papel constitutivo, mas apenas mediador. Curiosamente, Bryan Magee (2002, p. 226) diz concordar com Schopenhauer que a linguagem não teria um papel constitutivo no pensamento. No entanto, como mostrou Arno Ros (1979 e 2005), a conceituação mais sensata está no meio termo. De fato, a linguagem não é ainda constitutiva se estivermos falando dos estados mentais vinculados ao 
comportamento sensoriomotor, pois animais sem linguagem podem sim ter crenças e intenções. No entanto, a partir do momento em que começamos a nos apresentar como um si-mesmo (self) para outros falantes e a utilizar conceitos ${ }^{2}$ e os termos conceituais a eles vinculados, a linguagem passa a ser simplesmente indispensável, e ela tende a englobar o que antes era apenas sensoriomotor. Só poderíamos dispensar a linguagem se tivéssemos capacidades telepáticas, mas isso então dispensaria a redação de textos...

Cumpre notar que no ensaio "Sobre a linguagem e as palavras" (Über Sprache und Worte) de Parerga e Paralipomena, Schopenhauer de fato se aproxima da concepção constitutiva (originalmente defendida por Herder e W. von Humboldt) ao discutir a utilidade do aprendizado das línguas clássicas. No final do breve ensaio, ele diz:

[...] na aprendizagem de uma língua estrangeira constroemse novos conceitos a fim de conferir sentido a signos novos; conceitos são diferenciados, que antes estavam associados em uma unidade difusa, pois só havia uma palavra para eles; relações, que até então desconhecíamos, são descobertas, pois a língua estrangeira designa o conceito por um tropos ou metáfora peculiar; inúmeras nuances, similitudes, diferenças e relações entre as coisas vêm à consciência por meio da língua recém aprendida; adquirimos então uma visão multifacetada de todas as coisas. ${ }^{3}$

Schopenhauer reconhece, portanto, que o poliglotismo é um meio direto de cultivação espiritual (ein direktes Bildungsmittel des Geistes), mas interessantemente, na sua justificativa, recai na posição mentalista de que o conceito deve ser dissociado da palavra (..., indem durch die Erlernung vieler Sprachen sich immer mehr der Begriff vom Worte ablöst.). Assim ressalta-se a concepção de um suposto pensamento puro que estaria desvinculado da linguagem.

Qual é a causa desta dificuldade? Talvez a posição intermediária, em que se reconhece, por um lado, o conhecimento, entendido enquanto atitudes proposicionais como crenças e intenções sensoriomotoras (que Schopenhauer chama de representações intuitivas), mas se concede, por outro lado, a constituição linguística de conceitos ou representações abstratas, pode ter parecido "contraditória" ou difícil de resolver teorica-

2 Na ciência cognitiva atual o conceito tende a ser entendido como habilidade psicolinguística porque a aquisição de um conceito envolve o desenvolvimento do discernimento sensorial mas também da capacidade de explicar as regras semânticas vinculadas ao termo conceitual em questão por meio de exemplos. Assim, ter o conceito de cavalo é ser capaz de explicar a um interlocutor como se podem reconhecer tais seres. 
mente sem uma teoria genética de estágios de desenvolvimento como vemos em Piaget. Mas dado que o desdobramento da coisa-em-si ou Vontade se dá também em graus de complexidade crescente, parece-me que deve ter prevalecido o modelo mentalista radical pois teria parecido mais tranquilo e consistente simplesmente falar de conceitos enquanto representações de segundo grau sem ter que introduzir a linguagem nessa passagem como tendo função constitutiva.

Como decorrência desta semântica mentalista e representacionalista, o discurso metafísico schopenhaueriano tem sim sentido, mas é um sentido ambíguo ou equívoco. Falar sobre a coisa-em-si já por si não deveria ser possível sem que esse discurso fosse formulado a partir de alguma perspectiva. Um falante que tenha a pretensão de nos dizer como é a realidade em si precisa mostrar como tem esse suposto acesso para que possamos verificar suas afirmações. Mas isso não é possível, porque o que ele diz estar interpretando como realidade em si é uma visão pessoal, construída intersubjetivamente na nossa interação linguística. Daí resultam diversos paradoxos no sistema schopenhaueriano honestamente apontados por Magee (2002, p. 230s). Como alertava o Wittgenstein tardio, quando deixamos a linguagem operar irrefletidamente, podemos ser levados a buscar estabelecer cadeias dedutivas sem termos antes controlado adequadamente o sentido dos termos conceituais que utilizamos. Na nossa compreensão cotidiana, o corpo nos dá sim acesso imediato a estados sensoriais e perceptivos no tempo, mas isso de modo algum constitui um acesso privilegiado à coisa-em-si, pois qualquer um deveria poder verificar nossas afirmações a respeito. Schopenhauer mesmo reconhecia que o conhecimento da coisa-em-si seria a rigor impossível, pois todo conhecimento diz respeito a fenômenos e onde começa a coisa-em-si termina o conhecimento. Assim, mesmo nosso conhecimento de nós mesmos por introspecção seria conhecimento fenomenal, não numenal (cf. Magee 2002, p. 130). Além disso, qualquer suposto conhecimento metafísico daí adquirido teria que ser expresso por meio de atos linguísticos, o que não é possível apenas por meio de representações mentais. Não surpreende portanto que Schopenhauer negue que o sujeito possa conhecer a si mesmo como sujeito cognitivo, mas apenas como ser volitivo. A falta de reflexividade linguística se manifesta como uma impossibilidade de autoconhecimento reflexivo por via conceitual.

Do ponto de vista ontológico, o fato de sermos coisa-em-si tampouco altera o requisito de que qualquer conhecimento conceitual teria que ser constituído linguistica- 
mente para algum sujeito, não podendo ser absoluto. $\mathrm{O}$ conhecimento imediato que temos de nós mesmos a partir de dentro permanece autoconsciência que nada garante acesso intersubjetivamente controlável à coisa-em-si. Por fim, o emprego polissêmico dado por Schopenhauer ao termo 'vontade', vinculando-o à coisa-em-si, produz uma anomalia gramatical. Ele entende perfeitamente que a vontade e a autoconsciência não podem nos dar conhecimento da coisa-em-si por estarem inseridos no tempo fenomenal. Deste modo, dado que já havia o termo 'coisa-em-si' ou 'númeno', é desaconselhável seguir a proposta schopenhaueriana de ampliar o sentido do termo 'vontade' desta maneira. Ao mantermos o termo kantiano, garantimos uma compreensão teoricamente consistente dos problemas. Magee (2002, p. 142) reconhece quatro confusões conceituais assim geradas: (a) vontade confundida como sentido interno; (b) vontade confundida como personificação; (c) vontade confundida como consciência; e (d) vontade confundida como intenção direcionada. Magee (2002, p. 144) sugere que os termos 'força' ou 'energia' teriam sido melhores, o que não me convence tanto assim, ${ }^{4}$ mas ele ainda capitula perante o dever, que me parece inarredável, de corrigir Schopenhauer no seu conceito central. ${ }^{5}$

Por fim, ao fecharmos as vias de confusão linguística que tornam possível a metafísica schopenhaueriana, seria importante deixar claro que o que se perde com isso não é o sentido da vida, mas o que o Wittgenstein tardio chamaria de uma ilusão gramatical. Nós conhecemos sim a realidade, mas a realidade como ela se afigura conceitualmente para nós, dado o modo como a interpretamos por meio de conceitos presentes $a$ priori na nossa linguagem natural. Podemos, portanto, ser realistas, desde que relativistas, pois sempre haverá a mediação seja do corpo, dos sentidos, da mente, e da linguagem nessa relação com o mundo exterior. O que é impossível é uma cognição direta da realidade em si, por assim dizer absoluta porque supostamente isenta de qualquer relação ou mediação. Neste realismo relativista, porém, o conhecimento metafísico tem sentido mas mais se entendido enquanto o auto-esquecimento do sujeito cognitivo que, ar-

4 Schopenhauer deixa claro no $\$ 22$ de $O$ mundo como vontade e representação que, ao invés de subsumir a vontade sob o conceito de força, quer fazer o contrário.

$5 \quad$ Até mesmo Kant, ao traçar as duplas de distinções entre o a priori e o a posteriori por um lado e o analítico e o sintético por outro, deixou obscuro qual delas teria prioridade na sua teoria do juízo. Como sugere Arno Ros (1991), porém, uma reflexão mais cuidadosa deixa claro que a distinção prioritária é a entre o a priori e o a posteriori, pois é sobretudo entre os juízos a priori que iremos depois introduzir a distinção do analítico e sintético. As expressões 'juízo analítico a priori' e 'juízo sintético a priori', entretanto, fomentam essa confusão, fazendo com que se debata entre os diversos tipos de 'juízos sintéticos' (cf. C.S. Peirce). Para evitarmos tais expressões que induzem ao erro, devemos utilizar a expressão 'juízo $a$ priori analítico', assim como 'juízo a priori sintético'. E devemos também falar sempre de 'númeno' ou 'coisa-em-si' quando Schopenhauer fala de 'Vontade'. 
gumentando irrefletidamente num jogo de linguagem confuso, se ilude sobre o estatuto epistêmico de suas próprias asserções.

Cumpre contudo deixar claro que ao recusarmos conceder a Schopenhauer um sentido numenal para seu discurso, dado que, como ele mostrava ter plenas condições de entender, seria falar sobre o inefável e conceber o inconcebível, seria pobreza de espírito não reconhecer a sua fecundidade. É difícil evitar a impressão de que Schopenhauer tinha clara consciência até mesmo do que hoje podemos considerar erros na sua argumentação. Ao contrário da maioria dos filósofos, inclusive Kant, que podem cometer erros devido à incapacidade de obter a clareza e sistematização conceitual suficientes, os erros schopenhauerianos parecem mais como opções teóricas deliberadas, pois ele demonstra no decorrer de seu texto estar ciente não só das objeções às quais teria que responder mas também às consequências sistemáticas que elas acarretariam no resto do seu pensamento. E tudo isso redigido em um estilo exemplarmente claro e envolvente.

\section{A apropriação wagneriana da filosofia schopenhaueriana (Borchmeyer e Hammermeister)}

A metafísica do belo sofre um duro golpe já com o célebre ataque de Hanslick (1989) à subordinação das artes particulares a um sistema. Seguindo Grillparzer e condenando Schumann, ele defende ao invés da sistematização metafísica o que ele chama de "investigação científica", fundada no postulado de que em cada arte particular as leis do belo seriam inseparáveis do seu material e de sua técnica. A metafísica da música seria então remetida à esfera dos "sonhos opiáceos" de Wagner e Liszt, visionários de uma estética do sentimento que produziria música amorfa e heteronimamente determinada por textos. Desde então, os músicos têm tido poucas razões para associar ao seu trabalho algum significado metafísico em sentido schopenhaueriano embora sempre encontraremos inevitavelmente aqui e ali resquícios de algum apelo platônico ao valor transcendente da música. Não só a metafísica, mas a crítica musical jornalística e mesmo a estética musical sofrem de um descrédito generalizado e não de todo injustificado, pois para o músico a prática interpretativa (ou performance) é absolutamente central para seu métier, enquanto que o falatório sobre música frequentemente se limita a termos genéricos e metafóricos. Não podendo controlar o discurso metamusical, resta ao músico se concentrar na sua arte e confiar nas suas intuições. 
Para Wagner, porém, que tinha um projeto cultural nacional de exportação, a coloração metafísica schopenhaueriana podia conferir à sua obra uma profundidade filosófica particularmente atraente. Em seu ensaio sobre o que é alemão, Wagner (1919) contrasta a música italiana, francesa e judaica com a alemã e defende que somente o espírito alemão teria conseguido se erguer à universalidade para o bem da humanidade. A tetralogia do Anel dos Nibelungos não seria portanto apenas um mito germânico, mas reivindicaria uma relevância universal para todos nós. Neste ponto insere-se o argumento schopenhaueriano de que, ao contrário das outras artes, que remetem a idéias platônicas como objetivação da coisa-em-si, a música seria a objetivação imediata da própria coisa-em-si. Em seu ensaio sobre Beethoven, Wagner pretende aprofundar a tese schopenhaueriana, pois alega que o filósofo, tendo sido leigo em música, não teria podido realizar um estudo suficientemente aprofundado da música de Beethoven. Falando do ato da criação musical, Wagner (1987, p. 25) explica que:

[...] a música já é por si mesma uma idéia do mundo, pois nela o mundo representa diretamente sua essência, ao passo que, nas outras artes, ela só é transmitida e representada pelo conhecimento. A única coisa a considerar é que a vontade individual, emudecida do artista plástico pela pura intuição, desperta, no músico, sob a forma de vontade universal que, sobrepondo-se à intuição, adquire a consciência de si mesma. ${ }^{6}$

Mais adiante, ele concede apenas ao santo um estado superior ao do artista músico, pois seria mais duradouro e imperturbável.

Até que ponto Wagner se manteve fiel a Schopenhauer? Segundo Dieter Borchmeyer (Borchmeyer 2002, p. 171-2), apesar de todos louvores ao filósofo, nem Wagner nem Nietzsche são realmente schopenhauerianos consistentes. Wagner tenta alegar que as analogias entre a música e as idéias do mundo fenomênico serviriam para fundamentar o drama musical, mas Schopenhauer deixa claro que a música teria apenas uma relação indireta com essas analogias, pois ela nunca expressaria o fenômeno, mas somente o em-si do fenômeno. Justamente por não dizer respeito às aparências, a música não seria afetada pelas exterioridades envolvidas no drama. Daí o seu elogio a Rossini, cuja música, mais tarde chamada de absoluta por Wagner, falaria por si sem a necessidade das palavras. A insistência de Schopenhauer na separação entre música e

6 WAGNER, Beethoven, p. 25. 
texto, garantindo a autonomia soberana e indiferente da primeira, sugeria um dualismo que tanto Wagner quanto Nietzsche precisavam transcender.

Na seção de Parerga e Paralipomena II sobre a metafísica do belo e a estética, Schopenhauer dedica um bom espaço para comentar sobre a música instrumental e a ópera. No que diz respeito à primeira, ele reafirma sua preferência pela melodia sobre a harmonia. Quanto à segunda, ele a explica como resultado de uma tentativa bárbara de aumentar o prazer estético por meio de um acúmulo de recursos. Ele avalia que a distração produzida pela encenação e pelo enredo afastam o espectador de uma apreciação musical adequada em modo similar ao que ocorre no balé. Schopenhauer nota que a massa orquestral e vocal mobilizada na ópera tinha resultados musicais limitados, dado que a escrita harmônica (fundamentalmente triádica com a exceção, notada por ele, do acorde de dominante com quatro notas) não era proporcionalmente enriquecida, mas apenas dobrada em oitavas superiores. A ópera seria então melhor entendida como uma invenção não-musical para espíritos não-musicais (... eine unmusikalische Erfindung zugunsten unmusikalischer Geister..., p. 511) e ter-se-ia tornado até em uma degeneração da música (... die Oper sei zu einem Verderb der Musik geworden. p. 512). Ele nota a dificuldade de combinar vozes com os timbres orquestrais e comenta sobre a dificuldade dos solos de cantores masculinos (tenores e barítonos) se projetarem adequadamente. Por isso, na sua avaliação, as árias solistas seriam realizadas melhor pelas cantoras sopranos e mezzo-sopranos, e que as vozes masculinas funcionavam melhor como suporte harmônico. Mozart e Rossini permaneciam para ele os grandes mestres do gênero. A missa teria a vantagem sobre a ópera de não sofrer tanta interferência de um texto dramático: palavras como aleluia, gloria, amém, etc. poderiam ser musicalizadas como um solfejo mais livre e interessante. Só poderíamos obter um prazer estético musical completo então a partir de missas e de sinfonias, mas não de óperas. Schopenhauer sugere que se tente reduzir as óperas a um ato de uma hora, pois depois de duas horas de música contínua, o ato final se tornava um martírio para todos, público e músicos inclusive.

Ao mesmo tempo, a concepção schopenhaueriana da ópera não deixa de ter seus problemas. Para Kai Hammermeister (2002, p. 125), o problema maior é que a teoria schopenhaueriana das artes é completamente ahistórica. Por isso, ele não consegue dar conta de processos de mudança ou desenvolvimento. Como Goethe, e diferentemente de Schiller, ele rejeitava a história como categoria útil de pensamento. 
As variações múltiplas da história precisam então ser tratadas como meras formas aparentes e acidentais da idéia, sem pertencer a ela, mas apenas à sua representação enquanto objeto de cognição individual e como algo estranho e inessencial. Schopenhauer, porém, procura caracterizar a ópera como degeneração da música devido à introdução de elementos conceituais e discursivos. Mas em uma concepção rigorosamente ahistórica ou a ópera já deveria ter sido caracterizada como forma mista de poesia e música, ou deveria desconsiderar a tal suposta corrupção da música como sendo irrelevante, pois mudanças históricas não atingiriam formas transhistóricas. Hammermeister destaca também o individualismo schopenhaueriano, que seria bem distinto do coletivismo wagneriano.

\section{Considerações finais}

A filosofia da música, sobretudo na versão analítica, distingue hoje claramente entre as subáreas estética, semântica e ontológica (cf. Scruton 1997). Não é possível dar conta de todos os problemas suscitados pela metafísica schopenhaueriana da música, e por isso limitei-me a alguns pontos somente. Wittgenstein que, como demonstra cabalmente Magee, foi muito influenciado e, como Nietzsche, educado por Schopenhauer, também ocupou-se de problemas como o da compreensão musical. Mas quando retornamos ao segundo volume de Mundo como Vontade e Representação e lemos, no capítulo 39 sobre metafísica da música, que:

\footnotetext{
Porque a música não apresenta como todas as outras artes as idéias ou estágios da objetivação da vontade, mas apresenta imediatamente a vontade mesma; assim se explica porque ela tem um efeito imediato sobre a vontade, isto é, os sentimentos, paixões e afetos do ouvinte, de modo que ela as rapidamente eleva ou altera. ${ }^{7}$
}

Torna-se difícil não sentir que está nos sendo dada uma explicação inadequada sobre um fenômeno que hoje é amplamente investigado pela psicologia e neurologia da música utilizando todo tipo de aparelhos de imageamento cerebral. Cumpre admitir que não temos a explicação metafísica que Schopenhauer exigiria, mas o ponto afinal é que uma tal explicação já por si não é sequer concebível, pois não temos como falar sobre a coisa-em-si. Infelizmente, temos que nos contentar com explicações psicológicas e so- 
ciológicas inclusive para o porque da própria busca humana pelo saber metafísico. ${ }^{8}$ Para muitos, a única alternativa à busca metafísica pareceria ser a de se entregar ao desespero do ceticismo. Mas na verdade isso é um equívoco, pois, como tentei apontar no início do meu texto, nós conhecemos a realidade, só que não podemos captar o que seria sua essência diretamente. Talvez devêssemos com Nietzsche questionar porque desejamos essa convicção tão forte que o conhecimento metafísico supostamente nos daria. Será isso sinal de fraqueza no espírito que busca se firmar em verdades eternas e absolutas? E o papel da música nisso tudo?

A filosofia, a música e a as artes certamente têm uma história venerável na tradição européia, e não há como negar a inserção profunda desta tradição na especulação metafísica e religiosa. Mesmo entendendo o processo de dissolução desta tradição no hedonismo consumista que domina nosso mundo contemporâneo, parece que não podemos mais simplesmente voltar ao passado, mas temos que plasmar um futuro digno para todos recuperando do passado aquilo que deve ser emulado e desenvolvido. A filosofia schopenhaueriana nos fornece um magistral exemplo de como isso pode ser feito apesar da tão radical fragilidade dos consensos no mundo atual.

\section{Referências bibliográficas}

BORCHMEYER, D. Richard Wagner: Theory and Theatre, Oxford: OUP, 1991.

HAMMERMEISTER, K. The German Aesthetic Tradition, Cambridge: CUP, 2002.

HANSLICK, E. Vom Musikalisch-Schönen: Ein Beitrag zur Revision der Ästhetik der Tonkunst. Wiesbaden: Breitkopf \& Härtel, 1989.

MAGEE, B. The philosophy of Schopenhauer. Revised and enlarged edition. Oxford \& NY: Oxford University Press, 1983.

ROS, A. Objektkonstitution und elementare Sprachhandlungsbegriffe. Königstein: Hain, 1979.

ROS, A. Kants Begriff der synthetischen Urteile a priori. Kant-Studien. 2, p. 146-172, 1991.

\footnotetext{
7 SCHOPENHAUER, A. MVR, II, §39, p. 521, minha tradução.

8 Acredito que esta explicação resida no que seria a constituição dionisíaca do humano adulto, que o conduz à busca de diversos tipos de êxtases: cognitivo (ilustrado por Arquimedes ao gritar Eureka! e sair nu do banho ao ter resolvido um problema), místico-religioso, sexual, estético, político etc.
} 
ROS, A. Materie und Geist. Eine philosophische Untersuchung. Paderborn: Mentis, 2005.

SAFRANSKI, R. Schopenhauer und die wilden Jahre der Philosophie. München/Wien: Carl Hanser Verlag, 1987.

SCHOPENHAUER, A. Parerga und Paralipomena II, Wolfgang Frhr. von Löhneysen, editor, v. 5, Frankfurt am Main: Suhrkamp, 1986.

SCHOPENHAUER, A. Die Welt und Wille als Vorstellung Gesamtausgabe, L. Lütkehaus, editor, München: DTV, 2002.

SCHOPENHAUER, A. O Mundo como Vontade e como Representação. Primeiro Tomo. J. Barboza, tradutor. São Paulo: UNESP, 2005.

SCRUTON, R. The Aesthetics of Music. Oxford: Oxford University Press, 1997.

WAGNER, R. Beethoven. T. Tostes, tradutor, Porto Alegre: L\&PM, 1987.

WAGNER, R. Was ist deutsch? (1865-1878), Gesammelte Schriften und Dichtungen in zehn Bänden, W. Golther, editor, Berlin-Leipzig-Wien-Stuttgart: Deutsches Verlagshaus Bong \& Co., 1919. 